\title{
O WEBDOCUMENTÁRIO COMO UM DOCUMENTÁRIO FEITO DE UMA NARRATIVA INTERATIVA, HIPERTEXTUAL E PARTICIPATIVA
}

\author{
Tatiana Levin*
}

Resumo: Tratamos neste artigo do webdocumentário como uma narrativa interativa e hipertextual. Queremos verificar como o engajamento do espectador-usuário em um ambiente digital participativo reconfigura o espaço da produção. Investigamos ainda o tipo de experiência proporcionada em uma narrativa multissequencial.

Palavras-chave: webdocumentário, interatividade, hipertexto, autoria, participação, play.

Resumen: Tratamos en este artículo del webdocumental como una narración interactiva e hipertextual. Queremos comprobar cómo el compromiso del espectador-usuario en un entorno digital participativo reconfigura el espacio de la producción. Además, investigamos el tipo de experiencia proporcionada en una narración multisecuencial.

Palabras clave: webdocumental, interactividad, hipertexto, autoría, participación, play.

Abstract: In this article I discuss the webdocumentary as an interactive and hipertextual narrative. My aim is to observe how the spectator-user engagement in a participatory digital environment reconfigures the space of production. Plus I investigate the kind of experience provided by a multisequencial narrative.

Keywords: webdocumentary, interactivity, hypertext, autorship, participation, play.

Résumé: Dans cet article, le webdocumentaire est abordé comme un récit interactif et hypertextuel. Nous voudrions vérifier comment l'engagement du spectateur-utilisateur dans un environnement numérique participatif reconfigure l'espace de la production. On étudie également le genre d'expérience fournie dans un récit multi-séquentiel.

Mots-clés: webdocumentaire, interactivité, hypertexte, auteur, participation, play.

\footnotetext{
* Doutoranda. Universidade Federal da Bahia - UFBA, Faculdade de Comunicação, Programa de Pós-Graduação em Comunicação e Cultura Contemporâneas. 40110060, Salvador, Brasil. E-mail: tatianalevin@gmail.com
} 


\section{Introdução}

O documentário interativo embora seja um fenômeno recente como produto midiático incorporado ao campo da cultura e entretenimento apresentou avanços na produção de um corpo crítico de textos que buscam entendê-lo. ${ }^{1} \mathrm{O}$ cenário era diferente há menos de cinco anos atrás, quando a reflexão sobre o fenômeno encontrava-se repleta de indefinições e suposições. ${ }^{2}$ Questões que desde um primeiro momento se mostraram importantes tiveram avanços significativos, como o pensar no documentário interativo em termos de ser uma experiência colaborativa, ${ }^{3}$ mas que ainda pode ser espaço para uma visão autoral.

O documentário interativo designa uma mudança estética ao organizar o conteúdo em níveis de interatividade a estabelecer funções para o espectador-usuário ${ }^{4}$ dentro de diferentes possibilidades de participação. Por meio de uma organização hipertextual, a narrativa é apresentada de forma não-linear em seções de informação ligadas entre si. O interator é ativo na decisão da quantidade de material que quer usufruir e em qual

\footnotetext{
${ }^{1}$ Recente pois presente em grandes conglomerados midiáticos em fins da primeira década dos anos 2000. Um dos primeiros webdocumentários a ganhar alguma notoriedade foi Prison Valley, projeto de 2008 do canal ARTE (Disponível em: http://prisonvalley.arte.tv/?lang=en.).

2 Algo que retratei em artigo publicado ainda em 2013 ("Do documentário ao webdoc: questões em jogo num cenário interativo" in Doc On-line: Revista digital de cinema documentário, www.doc.ubi.pt, n. 14).

${ }^{3}$ Colaborativa no sentido de permitir o uso de conteúdo gerado pelo usuário. Como esclarece Sandra Gaudenzi (2014), trata-se de uma participação que vai além de uma interatividade baseada em clicar, selecionar ou escolher em meio a um conteúdo existente, significando portanto um adicionar ou mudar este conteúdo, interferindo assim no projeto.

${ }^{4}$ Defendi o uso da terminologia espectador-usuário em apresentação na SOCINE de 2013. Apesar de achar esta terminologia bastante apropriada na definição daquele que interpreta e navega por um documentário interativo, preservei e adotei termos variados utilizados por outros autores tais como leitor, escritor (Landow) ou interator (Gifreu, Murray), usuário (Gaudenzi, Nash, Gifreu) e prosumer (Gaudenzi). "Prosumer" é uma terminologia em inglês derivada do termo "consumer" e designa especificamente a audiência no contexto de mídias colaborativas, significando ainda "(...) permitir que o conteúdo gerado pelo usuário faça parte do conteúdo do documentário" (Gaudenzi, 2014).
} 
ordem. Sua participação pode dar-se em uma interatividade qualificada como reativa, quando o que se faz é clicar e fazer avançar o conteúdo, ou em um nível mais sofisticado, quando ele adiciona material como comentador ou criador, a ser moderado por vezes por um autor a exercer o papel de curador do material adicionado. É da ordem da autoria a arquitetura do projeto onde os níveis de interação são estabelecidos e é nesta arquitetura que está prevista ou não a possibilidade do espectador-usuário de se tornar um produtor de conteúdo.

Reflexões com base no objeto literatura digital numa configuração de hipertexto trazidas por George Landow no livro Hipertext 3.0 (2006) servem hoje para um entendimento da relação entre autoria e participação no documentário interativo, na ideia da configuração de um leitor muito ativo ou do leitor como escritor. Pensar a origem do hipertexto convoca textos seminais sobre novas mídias de Ted Nelson, responsável pelo termo hipertexto e sua concepção original ainda em 1960, e Vannevar Bush na sua elaboração sobre o memex em 1945, uma máquina que permitiria a associação de textos entre si de uma forma orgânica tal como a mente humana e onde o leitor poderia adicionar documentos nesta rede de informação fazendo anotações quando desejasse. Para Landow (2006: 11) o que é marcante na concepção original de Bush é primeiramente o reconhecimento da "leitura como um processo ativo que envolve escrever" e em segundo lugar a necessidade de um suporte virtual em lugar da estrutura física do livro. Landow cita como referência dois textos de $\mathrm{Bush}^{5}$ onde o autor introduz termos como link e a noção de blocos de textos ligados por links. O autor enfatiza a importância da contribuição de Bush na elaboração de uma nova textualidade em que um texto flexível está aberto às demandas de cada leitor. Nelson e Bush são assim pioneiros na concepção do que seria o hipertexto tal como o conhecemos ao terem percebido seu potencial “(...)

\footnotetext{
${ }^{5}$ As we may think (1945) e Memex revisited (1967).
} 
de permitir que usuários achem, criem, e sigam múltiplas estruturas conceituais num mesmo corpo de informação" (Landow, 2006: 10).

O meio digital por ser naturalmente participativo (Murray, 2003) permitiu que as ideias teóricas dos pioneiros fossem testadas em produtos culturais. Neste artigo queremos examinar as características do webdocumentário como um documentário feito de uma narrativa interativa e hipertextual. Pretendemos ainda averiguar o que ocorre na experiência de acesso a um documentário interativo do ponto de vista do que está previsto na arquitetura do projeto. Entendemos que as diferentes possibilidades de participação do espectador-usuário previstas pelo autor podem reconfigurar o espaço da produção. É importante assim entender essas novas relações. Dito de outro modo, queremos perceber as formas de participação do interator ao navegar por narrativas hipertextuais feitas de diferentes modos de interatividade.

\section{Um documentário não-linear e interativo}

Arnau Gifreu em uma série de textos sob o tema The distinction between linear and interactive documentaries publicados no Research Forum do Mit Open Documentary Lab (2013) fez um esforço de sistematizar as diferenças entre documentários tradicionais (lineares) e documentários interativos (não-lineares). Se há diferenças entre ambos, o documentário interativo segue correspondendo-se com o gênero documental ao ser um meio de representação da realidade histórica trazendo reflexões sobre temas relevantes da cultura humana. Gifreu refere-se à definição de documentário tomando a elaboração de Stella Bruzzi que fala numa “(...) negociação com a realidade, uma mescla da realidade da experiência do cineasta com seus esforços de compreendê-la" (Gifreu, 2012: 261-262). O autor ressalta que Bruzzi encara o realizador como uma figura central, pois sua definição incorpora uma mudança de paradigma sobre o que vem a ser o 
gênero no sentido de ter se deslocado de uma representação da realidade para uma ordenação e então negociação da mesma. Nas palavras de Gifreu, "Bruzzi vê o cineasta como se invadisse um espaço e o marcasse, deixando atrás a ilusão do 'cinema objetivo' que inspirou o cinema direto dos anos sessenta" (Gifreu, 2012: 262, grifo do autor). A subjetividade do realizador é incorporada ao resultado fílmico nessa mescla da sua própria realidade com a tentativa de retratar a realidade histórica em foco. Bruzzi dialoga com uma tradição de estudos do campo do documentário onde a superação do ideal de objetividade é vista como um avanço na compreensão do gênero. Importante observar que se a definição de Bruzzi traz progressos ao situar a representação da realidade no documentário como fruto da subjetividade de um realizador, ela ainda lida com um contexto onde um espectador participante não é uma questão a mexer com o espaço da prática. Mandy Rose (apud Gifreu 2013-2014) reforça essa visão de historicidade baseada na ideia de evolução presente na reflexão teórica de autores ocidentais reconhecidos no campo de estudos sobre documentário. Rose situa o documentário interativo como uma evolução no modo de representar a realidade. A evolução do documentário para ela seguiu até o século XX dentro de uma intenção de gerar significado a partir de um autor modelando uma peça. A forma estava organizada segundo o modelo de início, meio e fim nos documentários lineares. Outras possibilidades surgiram com a lógica interativa componente do documentário interativo, propiciando por exemplo o surgimento de peças mais dialógicas, colaborativas e abertas. Podemos perceber nessa fala de Rose que são outras as questões levantadas para se entender o produto documentário interativo. $\mathrm{O}$ foco sai do texto como peça acabada a ser analisada para incorporar ainda uma negociação, mas entre autor e usuário a modificar este texto. A importância do autor neste caso estaria também ligada ao tipo de experiência proporcionada durante o acesso.

O documentário dentro de um meio interativo faz referência aos 
temas e sujeitos da realidade histórica, porém promove outro tipo de experiência para aquele que passa a ser além de audiência um usuário que tem opções de controle sobre o material. Segundo Gifreu (2012), a mudança dá-se no sentido de transferência de opções de eleição e controle que antes eram propriedades somente do documentarista. Tomando de Bill Nichols o princípio de definir o documentário por meio dos eixos de observação autor, texto e espectador, ele aponta a não-linearidade como uma diferença fundamental entre o documentário tradicional e o interativo. A questão da linearidade sob o ponto de vista da sua manifestação textual colocaria em pontos opostos as duas modalidades de documentário, sendo impossível modificar a ordem do discurso no documentário tradicional quando finalizado para exibição e distribuição. Falar de linearidade para Gifreu diz respeito a se pensar numa rota fixa pré-determinada pelo autor que vai de um ponto inicial até um ponto final. A não-linearidade opera numa lógica diferente, onde se pode ter um ponto inicial estabelecido pelo autor ou escolhido pelo usuário que irá derivar em caminhos e ramificações múltiplos, dependentes da rota escolhida. Trata-se de diferentes narrativas possíveis, um discurso fragmentado em opções variadas, onde há um poder de decisão nas mãos do interator.

O documentário linear demanda apenas um tipo de envolvimento cognitivo da audiência, um envolvimento mental que resulta numa interpretação e reflexão sobre o visto, enquanto que o documentário interativo requer, além da interpretação cognitiva, um tipo de participação física e processo de decisão relacionados que resulta no uso do mouse, movimentar-se por um cenário virtual, ou uso do teclado e escrita, fala, etc. (Gifreu, 2013, parte 1).

O autor finaliza sua reflexão comparativa sobre documentários lineares e interativos ressaltando suas similaridades no uso de convenções de representação textuais como o uso de entrevistas, de sequências 
observacionais, ${ }^{6}$ comentários em voz over ou na forma de textos. E se eles ainda podem ser organizados em torno de um forte apelo narrativo ou em múltiplas histórias categorizadas, há uma diferença fundamental no arranjo temporal dos itens numa nova organização espacial-temporal dos conteúdos não ficcionais agora remediados. ${ }^{7}$ Segundo Mike Robbins (apud Gifreu, 2013-2014), a experiência do documentário interativo é ser uma plataforma que permite o consumo de outras mídias numa única janela. O consumidor deste tipo de produto seria alguém acostumado a lidar com diferentes mídias.

\section{Uma narrativa hipertextual}

Ao discutir o futuro da narrativa no ciberespaço, Janet Murray (2003) lembra da importância da narrativa para a ordenação cognitiva da experiência humana e de como o formato participativo natural do ambiente digital promove um envolvimento diferenciado quando comparado à experiência de se ouvir ou assistir a uma história sem interatividade. Ao definir o formato da narrativa interativa, Murray prefere o termo multissequencial ou multiforme para classificar histórias que se afastam de um formato linear convencional. Sua justificativa é que o termo não-linear é associado erroneamente com a falta de causalidade narrativa. Nas suas palavras, "histórias multissequenciais proporcionam ao interator a habilidade de navegar por um arranjo fixo de eventos de diferentes maneiras, todas elas bem definidas e significativas" (Murray, 2003: 10).

\footnotetext{
${ }^{6}$ Gifreu revisa os modos de representação documentais a partir de Bill Nichols tanto nesse texto quanto em sua tese, sendo o modo observativo um deles. Também revisei os modos de Nichols em artigo publicado na Doc On-Line em 2010, além da minha dissertação de mestrado (2009), a fim de entender questões de representação textual no campo do documentário.

7 "Remediação" é um conceito usado por Gifreu no sentido de Jay David Bolter e Richard Grusin significando “(...) a representação de um meio em outro (...) a remediação é uma característica das novas mídias digitais" (Bolter; Grusin, 2000: 45).
} 
Apesar das raízes do formato multissequencial terem sido plantadas em outros meios, Murray destaca o computador como lugar para uma audiência ativa, participativa, onde o formato do hipertexto tem sido adotado em larga escala. A dinâmica hipertextual permite aos autores experimentar possibilidades de encadeamento lógico dentro de um ambiente interativo e imersivo. O hipertexto funciona enquanto um sistema que permite que diferentes unidades semânticas possam ser ordenadas e reordenadas a partir de links que as conectam. ${ }^{8}$

A revolução trazida pela tecnologia da informação digital que teve início com o computador foi vista por pioneiros como propulsora de uma nova forma de escrita. Landow (2006: 144) explora alguns problemas de uma escrita hipertextual como o lidar com o sentido de desorientação que a experiência de navegação por um espaço digital pode proporcionar quando aquele que navega não sabe em que ponto está na rede ou como chegar a um ponto que sabe ou pensa existir. O autor ressalta que a desorientação embora seja reconhecida como problema pode ser vista também como um prazer estético. Problema ou efeito desejado, a desorientação é enfrentada no planejamento da navegação pelo espaço digital que abriga agora narrativas multissequenciais, onde achar o sentido de orientação engloba mais opções do que o avançar ou retroceder das narrativas lineares. Landow cita ainda a abordagem da experiência de navegação no espaço hipertextual digital por teóricos do hipertexto como o vaguear por uma base de dados.

O hipertexto e a hipermídia convocam para Landow questões de planejamento de sua arquitetura que devem responder a alguns desafios, já que é característica deste tipo de escrita o oferecimento de uma experiência

\footnotetext{
${ }^{8}$ Landow assume os termos hipertexto e hipermídia como similares, visto que para ele o hipertexto já expandia a noção de texto para além do verbal ao classificar a ligação de blocos de textos com outros materiais não verbais (imagens, mapas, diagramas, etc). Hipertexto designa assim um "texto composto de blocos de texto - o que Barthes nomeia uma lexia - e links eletrônicos que os unem” (Landow, 2006:3) e hipermídia expande essa noção ao qualificar também materiais não verbais como parte do sistema.
} 
que implica comportar mudanças de direção através da ligação (links) de blocos de informação. Assim, o autor pergunta (1) o que pode ser feito para ajudar os leitores a obter prazer e um sentido de orientação ao longo da experiência, (2) como eles podem ter seus passos rastreados no seu caminho de leitura, (3) como pode ser desenhada a estrutura dos links de forma que se possa saber onde eles levam e por último, (4) como alguém pode ajudar um leitor que acabou de entrar no projeto a se sentir em casa. Landow resume da seguinte forma os problemas colocados, tratam-se respectivamente de questões de orientação, navegação e informação sobre entrada e saída.

A questão geral aqui é sobre interpretação. Mais especificamente, permitir que visitantes desse novo tipo de texto o leiam prazerosamente, confortavelmente $\mathrm{e}$ eficientemente, quanta interpretação a mais o autor-designer deve adicionar ao sistema como um todo, para ligar caminhos, e os documentos ao fim dos links? (Landow, 2006: 153).

O autor indaga sobre o que é qualidade no hipertexto levantando algumas características do meio que o definem: multilinearidade, multivocalidade em potencial, riqueza conceitual e controle dado ao leitor. O conceito de multivocalidade é tratado por Landow (2006: 56) a partir da noção de Bakhtin sobre romance multivocal, onde múltiplas consciências interagem. No contexto de hipertexto, essa multivocalidade vista como potencialidade do meio é atribuída a uma propriedade dada na "leituraescrita", ou seja, na combinação entre a experiência de interpretação de um bloco de texto específico com a experiência do espectador-usuário que cria sentido através da navegação, considerada a construção de um caminho pessoal na narrativa.

Sobre a narrativa hipertextual, alguns pontos destacados servem para pensarmos o contexto da narrativa no documentário interativo. São eles o 
empoderamento do leitor, as escolhas e possibilidades de intervenção dadas a ele; o uso dos recursos textuais $;{ }^{9}$ a complexidade da estrutura da rede; e os graus de multiplicidade e variação em elementos literários como enredo, caracterização, contextualização e outros. Neste último ponto, o próprio Landow discute o uso da poética aristotélica no contexto do hipertexto como algo a ser tomado como referência para a percepção de uma certa desconstrução, já que a definição de Aristóteles de enredo é baseada no princípio da sequência fixa para falar de início, meio e fim. O trecho da poética citado por Landow embasa sua reflexão:

Um todo agora é aquilo que tem início, meio e fim. Um início é aquilo que não é em si necessariamente depois de nada mais, e que tem algo naturalmente depois dele; um fim é aquilo que naturalmente é depois de algo bem como é necessariamente ou usualmente consequente, e sem nada mais depois dele; e um meio é por natureza depois de uma coisa e também tem outra coisa depois de si. (Aristóteles apud Landow, 2006: 218).

Landow (2006: 218) fala ainda de como um todo segundo Aristóteles deve apresentar "uma certa magnitude definida" para ser belo, além da ordenação das partes constituintes citadas. Assim, o autor estabelece que o hipertexto desafia a sequência fixa, o início e fim definidos, "uma certa magnitude definida" na história e, por fim, a própria concepção de unidade ou de um todo associadas aos outros conceitos. Tomando a poética aristotélica como referência, o autor inicia uma reflexão sobre a própria natureza da conceituação de narrativa dentro de um critério de linearidade, onde a qualidade da multilinearidade do hipertexto requer uma outra visão sobre o papel do leitor.

\footnotetext{
${ }^{9}$ Landow fala em recursos extra-linguísticos textuais já que seu foco está em literatura e portanto no uso do verbal como matéria fundamental. Adotamos aqui o sentido de texto como materiais verbais e não-verbais, especificando-os quando necessário para a reflexão em curso.
} 
Um dos pressupostos do hipertexto é que o linkar prepara o leitor para uma interpretação relacional. Landow posiciona o usuário (espectador, leitor) da narrativa multissequencial como aquele que produz linearidade através da sua leitura, da sua experiência de navegação: “(...) todas as experiências de leitura e escrita em quaisquer meios são num sentido importante lineares, unidirecionais" (Landow, 2006: 152). A linearidade então passa a ser vista como uma habilidade do leitor dada na experiência de interpretação/leitura do material hipertextual no contato com um bloco de textos ou no seguimento de caminhos. Um leitor mais ativo na interpretação do conteúdo ganha novas habilidades a depender do desenho do sistema hipertextual.

Problemas adicionais surgem quando considera-se que o hipertexto envolve um leitor mais ativo, alguém que não apenas seleciona caminhos de leitura mas que também tem a oportunidade (em verdadeiros sistemas leitura-escrita) de ler como alguém que cria um texto; a qualquer momento a pessoa que está lendo pode assumir um papel autoral e também anexar links ou adicionar texto ao texto que está sendo lido. (Landow, 2006: 82).

A reconfiguração do autor dentro de um sistema hipertextual é para Landow uma potencialidade e não uma propriedade automática. No contexto que nos interessa do documentário interativo, a autoria e participação têm sido objeto de reflexão de pesquisadores que tratam especificamente do tema. Um espectador-usuário pode assumir posições variadas a depender do uso da interatividade em níveis e propostas diferenciadas. 


\section{A interatividade aplicada ao documentário, os limites da participação e o exercício da autoria}

As opções de engajamento do espectador através da sua participação na narrativa têm sido exploradas no documentário interativo. Kate Nash no texto Clicking the world: documentary representation and interactivity (2014) explora o conceito de interatividade na sua complexidade pensando como interagir com um documentário é diferente do lidar com outras formas midiáticas no que concerne à experiência proporcionada. O uso da interatividade não apenas distingue o documentário interativo de seus pares televisivos ou cinematográficos, mas promove mudanças no texto em si e em formas de engajamento diversificadas segundo a autora.

Muitas vezes a interatividade é entendida em termos do que a audiência, agora crescentemente descrita como usuários, é capaz de fazer em relação ao conteúdo do documentário. Frequentemente, o significado das ações do usuário é descrito em termos políticos ou epistêmicos: audiências são ativas, empoderadas, profundamente engajadas e o documentário transcendeu suas raízes modernistas finalmente evitando a totalidade e criando espaços nos quais os indivíduos podem falar por si mesmos. (Nash, 2014, grifo do autor).

A autora considera que o ambiente do documentário interativo é um ecossistema dinâmico composto por usuários, realizadores de documentário, assuntos e sistemas tecnológicos, onde a interatividade propicia engajamentos narrativos que derivam em efeitos também diversificados. Dentro deste contexto, algumas das perguntas que Nash quer responder é o que as audiências podem fazer com o conteúdo do documentário, como são endereçadas e posicionadas e o que podem experienciar. Ela distingue para isso as dimensões tecnológica, relacional e experiencial no entendimento da interatividade. Uma quarta dimensão lida com a especificidade do discurso 
do documentário pensando-se a questão da voz, no agenciamento do usuário e no potencial retórico da interação.

Perceber como a tecnologia dá forma a experiência do usuário é o que Nash quer contemplar com a dimensão tecnológica. Dito de outra forma, esta dimensão permite verificar o grau de resposta do sistema tecnológico, sua abertura, as escolhas que ele disponibiliza, e a extensão do controle do usuário sobre o documentário enquanto um sistema. A autora faz referência aqui a Sandra Gaudenzi $(2013)^{10}$ e aponta principalmente o empenho físico requisitado do usuário para fazer o documentário funcionar. Outro destaque na dimensão tecnológica é a presença de affordances ${ }^{11}$ no produto que eventualmente não são utilizadas, quando a audiência é convidada a participar e não adere à proposta mesmo se sentindo capaz.

A dimensão relacional colocada por Nash convoca o entendimento da interatividade como um relacionamento tanto entre máquina e usuário quanto entre usuários que interagem entre si. Aqui interessa analisar como a dimensão tecnológica posiciona o usuário em relação ao documentário no sentido de verificar como ele é endereçado, de que forma é convidado a participar e em que tipo de ambiente comunicacional. Ela cita como características desse ambiente relacional a reciprocidade, a capacidade de resposta, igualdade e participação. Assim interessa avaliar quem fala, a extensão da reciprocidade e como a audiência é posicionada nessa troca.

O documentário interativo estabelece uma posição específica da audiência em relação ao seu conteúdo tendo como premissa a participação do usuário da maneira esperada. Para Nash (2014), "isso pode ser manifestado na forma de instruções específicas ou pode ser implícito, na aposta de familiaridade com metáforas e processos que cercam as

\footnotetext{
$10 \mathrm{Na}$ sua tese de doutorado: The living documentary: from representing reality to cocreating reality in digital interactive documentary (University of London).

${ }^{11}$ Segundo Janet Murray, affordances são as propriedades funcionais que permitem usos particulares para a representação em narrativas interativas (Disponível em: http://inventingthemedium.com/glossary/.
} 
tecnologias comunicacionais digitais". A autora cita os fóruns de discussão presentes nos documentários interativos dentre as formas comunicacionais avaliadas na dimensão relacional. Nash traz como exemplo de análise os mecanismos de discussão como fóruns e chats no webdocumentário Prison Valley, onde os próprios habitantes da comunidade retratada utilizaram o espaço para questionar o ponto de vista dos autores do documentário. Analisando a situação, ela conclui que embora a audiência tenha sido engajada de forma ativa na discussão, o teor das respostas fornecidas pelos realizadores em sua defesa levanta questões de autoridade e enquadramento das contribuições dos espectadores.

Uma outra dimensão considerada pela autora trata de como os participantes experienciam a interação. A gama de quesitos a serem avaliados vai desde o quanto o sistema é percebido como rápido e responsivo ao grau de playfulness ${ }^{12}$ e conectividade com outros interatores. A experiência engloba a percepção de como a audiência entende o convite à participação e os significados apreendidos a partir do seu engajamento.

A dimensão discursiva da interatividade é adicionada por Nash na abordagem do documentário interativo como aquela que diferencia o estudo do documentário do de outras mídias interativas. Essa dimensão visa contemplar a análise da relação entre as ações dos usuários e o discurso do documentário, ou seja, examina até que ponto as ações dos usuários impactam de forma significativa o argumento proposto pelo documentário. Nash cita a fala de Nichols $(1991)^{13}$ sobre o documentário ser um discurso de sobriedade ao endereçar uma realidade compartilhada e fazer afirmações a serem tomadas como verdadeiras. Ainda sobre o autor, ela retoma o conceito de voz como "aquilo que traz o ponto de vista social do texto"

\footnotetext{
${ }^{12}$ Como play quando traduzido para o português qualifica os termos tanto brincar quanto jogar, além de atuar, preferimos assumi-lo na língua inglesa de forma a incorporar ambos significados. Joga-se e brinca-se quando se navega por uma narrativa interativa. Pode-se inclusive atuar como personagem inserido na narrativa. Mesma direção foi tomada em relação a playfulness. Podemos pensar em jogabilidade ou ludicidade.

${ }^{13}$ Representing reality: issues and concepts in documentary
} 
(Nichols apud Nash, 2014) para pensar a relação entre a autoria do documentário e o discurso. ${ }^{14}$ Nash lembra que noções tradicionais de autoria são desafiadas no ambiente interativo onde uma questão central é a interrogação da relação entre os argumentos suportados pelo documentário interativo e a ação da audiência. Para a autora, alguns webdocumentários ao se organizarem em categorias podem promover comparações retóricas. Um exemplo citado é Gaza Sderot com sua interface dividida contendo depoimentos de cidadãos palestinos de um lado e de israelenses do outro. ${ }^{15}$

Importante notar que Nash não propõe uma definição para o conceito de interatividade, mas uma visão multidimensional por meio de aspectos definidores e ferramentas para se indagar seu uso estratégico como recurso de representação da realidade. ${ }^{16}$ Para a autora é preciso pensar no engajamento do usuário no produto posicionando-o em relação ao discurso e planejando sua experiência em curso.

Outro texto que foca na dimensão participativa da interatividade tem autoria de Sandra Gaudenzi. ${ }^{17}$ Em Strategies of participation: the who, what and when of collaborative documentaries (2014) é ressaltada a importância de se planejar níveis de participação do usuário em documentários colaborativos já que nem todos desejam participar na mesma intensidade.

\footnotetext{
${ }^{14}$ Conceito desenvolvido por Nichols no texto A voz do documentário, publicado em 1983.

15 Alexandre Brachet (Upian), produtor de Gaza Sderot, relatou que apesar de ser tecnicamente possível permitir que comentários dos dois lados fossem ouvidos ao mesmo tempo, foi priorizado dar ao usuário a opção de escolher qual lado gostaria de ouvir a cada momento, se o palestino ou o israelense. (Between the Lines, 2013).

16 Murray (2003) já havia utilizado em 1997 uma definição múltipla de interatividade, destacando a dimensão procedimental e participativa do ambiente digital, algo também explorado no glossário de seu blog Inventing the medium: "The digital medium is participatory in allowing an interactor to manipulate, contribute to, and have an effect upon digital content and computer processing. Participation combined with procedurality create interactivity, which means that the designer must script the behavior of the computer and the behavior of the interactor".

17 Participação também se torna um conceito a ser destrinchado quando se fala em documentário interativo e neste sentido ganha outros contornos quando comparado ao uso dado por Murray (conferir nota anterior).
} 
Gaudenzi determina alguns critérios para avaliar níveis de participação, como a lógica de todos serem revisores ${ }^{18}$ da Wikipédia em oposição à edição feita apenas por um autor. Cada opção contém em si fatores a serem avaliados como a manutenção da coerência narrativa por exemplo. Uma lógica de produção que inclua a participação do usuário na adição de conteúdo resulta num documentário feito de uma base de dados crescente, porém sem lhe dar o poder de se envolver na arquitetura do projeto. É a possibilidade de todos contribuirem com o texto imagético ${ }^{19}$, mas sem o poder de agirem como co-autores no sentido de exercerem domínio sobre a edição e permanência de materiais no documentário final. Gaudenzi ressalta que para se construir a arquitetura do projeto é preciso habilidades de programação específicas, mas para ela o cerne da questão é outro: a arquitetura do projeto num documentário interativo é o lugar para a voz autoral, o controle da interface é portanto um novo nível de poder. "Nesse contexto a autoria é menos sobre a expressão de uma intenção particular (Foucault 2008: 53) ou sobre dar poder de interpretação ao leitor (Barthes 1984: 37) e mais sobre orquestrar níveis de agenciamento através do software" (Gaudenzi, 2014).

Permitir a contribuição do usuário em projetos interativos com conteúdo gera essa forma crescente de narrativa onde o problema passa a ser quando interromper o acréscimo de material e como dar uma forma final ao todo. Como ressalta a autora, a estética da forma final desse tipo de produto assemelha-se a um mosaico, onde múltiplas entradas podem ser visualizadas simultaneamente numa única interface. Sua crítica é justamente que há uma perda de detalhamento em meio à apresentação de uma heterogeneidade.

Comparando documentários lineares e interativos, Gaudenzi distingue diferentes modos de produção. Se o linear comporta as fases de pré-produção (pesquisa e ideias), produção (realização técnica, filmagem e

\footnotetext{
18 "Crowd-reviewing" no original.

19 "Crowdsourcing video" no original.
} 
edição) e pós-produção (lançamento e distribuição), o interativo diferenciase por conter durante a fase de produção outros focos de realização técnica (realização da plataforma, com codificação e produção de algum conteúdo ${ }^{20}$ ) e ao ser colaborativo, tenha uma fase posterior destinada à produção de conteúdo do usuário além da fase onde a plataforma digital é lançada com algum conteúdo.

Gaudenzi chama atenção para a importância de se pensar em quem está participando, o que pode ser feito e quando a intervenção é possível a fim de cercear as estratégias de participação em documentários interativos colaborativos. Para ela, decidir quem participa é fundamental para o autor do projeto em termos de quem ele chama para construir uma relação dialógica. O "quem" convoca o envolvimento dos participantes em relação ao assunto enquadrado pelo projeto, o quanto são experts em certo tópico ou companheiros com uma paixão em comum, ou apenas uma multidão de nãoexperts.

Documentários produzidos por muitos ${ }^{21}$ têm que lidar com três grandes desafios: como navegar através de uma grande quantidade de informação (interface), como criar uma narrativa coerente para o usuário final (experiência do usuário) e se e quando parar o acréscimo de conteúdo (ciclo de vida do projeto). (Gaudenzi, 2014).

Segundo Gaudenzi, uma variável no documentário interativo colaborativo é quando os participantes são os sujeitos retratados, quando então eles são diretamente selecionados pelo autor e envolvidos no retrato de si e limitados pelo acordo feito entre as partes durante o processo.

\footnotetext{
${ }^{20}$ Gaudenzi tem como foco no seu artigo os documentários interativos colaborativos e portanto define a produção de parte do conteúdo nessa fase. Documentários interativos que não aceitem a adição de conteúdo de usuários terão a produção de todo o conteúdo em uma única etapa.

${ }^{21} \mathrm{Na}$ nossa tradução o termo utilizado pela autora "crowd-produced" virou "produzido por muitos". Temos no entanto visto a presença corrente de termos como crowd-funding e crowd-sourcing mantidos no original em meios de comunicação em língua portuguesa.
} 
Outro fator destacado pela autora é como enquadrar a participação, sendo exemplos o adicionar conteúdo ao já existente, modificá-lo, interferir no projeto. Gaudenzi enfatiza as relações de poder nessa decisão, lembrando que adicionar conteúdo mudando o tamanho e a forma da base de dados não significa influenciar a arquitetura interativa e a interface do projeto. A autora conclui que, diferentemente dos documentários lineares, onde o que estava em jogo era uma visão particular do mundo, aqui o que importa é estabelecer uma posição no mundo. “'O que o participante pode fazer’ é uma proposta de ação, uma visualização de mudança, dentro de um mundo on-line que tem suas próprias regras e limites - normalmente estabelecidos pelo autor" (Gaudenzi, 2014).

Decisões relacionadas ao "quando" dizem respeito ao selecionar um período de tempo no qual o documentário interativo estará aberto à participação. Gaudenzi situa as fases de pré-produção e produção como aquelas onde a participação ainda é enquadrada sob um forte olhar autoral. Um exemplo é povoar uma interface estabelecida (conteúdo adicionado após lançamento da interface) resultando numa estética de mosaico. Isso muda apenas quando o documentário é construído numa dinâmica de mudança constante, onde o controle do projeto é também compartilhado.

Os mecanismos de participação num documentário interativo têm sido um importante foco de atenção da academia por mexer com uma questão fundamental do documentário, a autoria do seu ponto de vista social. Contudo, nem todos os documentários interativos investem na colaboração. Muitos se organizam em torno de uma base de dados fechada, onde a experiência implica uma interatividade restrita. A experiência no entanto requer ainda uma postura diferenciada do espectador. 


\section{Delimitações da experiência ao se percorrer um documentário interativo: o play e o vaguear}

Quando fala em navegação e especificamente em navegar por uma narrativa hipertextual, Landow (2006: 153) distingue que a navegação pressupõe localizar-se num mundo espacial e o hipertexto pressupõe um mundo experiencial onde algo desejado está sempre à distância de um link. Uma chave interessante de compreensão do documentário interativo é pensar como está enquadrada essa experiência de se transitar por um mundo construído num ambiente digital. Para Willian Uricchio, essa nova forma de contar uma história pode ser vista como herdeira do documentário linear, embora vindo de um espaço diferente daquele da tradicional realização cinematográfica, um espaço entre o documentário e o play (Gifreu, 20132014).

Uricchio apresenta no texto Playing with narrative dois conceitos que buscam dar conta da experiência do usuário enquanto percorre um documentário interativo, o de play e o de vaguear, andar ao acaso. ${ }^{22} \mathrm{O}$ autor cita Caspar Sonnen (diretor do IDFA DocLab) no uso do termo vaguear para explicar a diferença da experiência proporcionada por um documentário tradicionalmente linear e o interativo. Sonnen usa a noção de vaguear fazendo uma analogia com a visita a uma cidade acompanhada por um guia turístico em oposição à opção de se realizar a mesma visita por conta própria andando ao acaso, vagueando. Se a primeira opção corresponde a ter sua atenção direcionada por diferentes pontos previamente selecionados, a segunda opção conduz a um caminho de descobertas próprias onde seguir seu interesse leva à criação de uma história personalizada. São experiências diferentes proporcionadas em cada opção. "Elas oferecem diferentes affordances, atendem diferentes necessidades,

\footnotetext{
22 "Wandering" no original.
} 
requerem diferentes posturas" (Uricchio, 2013). E segundo Uricchio, ambas oferecem engajamento narrativo.

A noção de play é aquela onde o autor se detém mais demoradamente. Uricchio segue o trabalho de Scot Osterweil (diretor criativo do MIT's Education Arcade) que introduz a noção de play fazendo uma distinção entre as experiências de se ouvir um ótimo contador de histórias e de se jogar/brincar (playing). No primeiro caso, a experiência é deixar-se ser guiado pelo contador de histórias que apresenta cuidadosamente uma história amarrada. O play leva a outras experiências que vão de imaginar e co-criar um mundo e suas regras a habitar um personagem ou mesmo compartilhar objetivos com jogadores na mesma situação. A postura solicitada é a de se deixar levar sem se ter certeza do desfecho, sendo importante improvisar habitando personagens e vivendo-se a experiência que segue. Uricchio esclarece que Osterweil elabora essas analogias direcionadas a um objeto de estudo que são os games de computador criados para potencializar o aprendizado, e sendo assim, sua visão de play insere-se dentro de uma situação narrativa onde a história é desconhecida para o jogador que navega seu mundo diegético com suas regras, tendo um objetivo a atingir. A mesma noção aplicada ao estudo do documentário interativo requer outras considerações, embora dentro das possibilidades exploradas exista o jogar/brincar como personagem, situação referida por Osterweil como profundamente narrativa.

No seu interesse por entender o fenômeno do documentário interativo, Uricchio percebe a necessidade de se rediscutir o que é uma narrativa, já que o conceito de narrativa mais aceito na academia é aquele que lida com a narração de eventos ocorridos no passado não contemplando portanto algo em curso, como estar jogando/brincando ou experienciando uma situação ao se adquirir novas vivências. 
No sentido exato, nenhum "contador" de "eventos passados" significa nenhuma narrativa. E ainda nossa experiência enquanto vagueando ou playing pode parecer tão imersiva, instigante, motivada e coerente como qualquer história, e no caso do play, contém explicitamente muito das mesmas características (personagem, ambientação, regras, e um "assim como" mundo ficcional). Este último ponto, é claro, traz sua gama de complicações ao documentário, mas como irei sugerir, isso também oferece importantes formas de repensar o lugar da imaginação no domínio do não-ficcional. (Uricchio, 2013, grifo do autor).

Play trabalhado dessa forma é para Uricchio uma potencialidade a ser desenvolvida no campo do documentário via documentário interativo.

$\mathrm{O}$ autor lembra num breve histórico, que o surgimento dos games em torno de 1960 e de jogos ficcionais interativos em particular, por volta de 1970, mexem com formas narrativas tradicionais. O desenvolvimento sistemático de novas formas de narratividade é um fenômeno recente para ele, como atestam exemplos de filmes interativos em fins de 1980 (MIT's Interactive Cinema Research Group) e de literatura interativa em fins da década de 1990 (Electronic Literature Organization). Uricchio identifica três diferentes estratégias surgidas com o desenvolvimento dos games de computador e a emergência de formas narrativas que promoveram experiências de fruição alternativas nos anos 1980. As três estratégias descritas por Uricchio situam o documentário interativo a partir de diferentes concepções do conceito de narrativa.

A primeira estratégia traz uma relação com a noção corrente de que narrativa é o recontar de eventos passados. A atividade do jogador é redefinida ao se introduzir narratologicamente uma espécie de voz interior que tem a ver com a consciência do jogador ao andar ao acaso, vagueando por aí. Os eventos quando processados cognitivamente seriam algo como experienciados há pouco, portanto tecnicamente passado. Uma variação dessa abordagem toma o problema do "experienciado há pouco" e a natureza indeterminada das conclusões, argumentando que narrativa é o que 
é construído retrospectivamente, depois do processo estar completo, quando lembramos e recontamos nossas experiências.

A segunda estratégia afasta-se de uma teoria voltada para a grande narrativa para lidar com as micro-estruturas da narrativa.

(...) $\mathrm{O}$ processo pelo qual questões são repetidamente colocadas e então respondidas de forma a sustentar o interesse do espectador e fazer avançar a narrativa geral. Em vez de pensar a narrativa como uma estrutura englobadora da experiência total (seja o "começo, meio e fim" de Aristóteles ou Freytag), pode em vez disso ser entendida como os blocos construtores de uma experiência, cada um com seu ciclo de "exposição, transformação e resolução". (Uricchio, 2013, grifo do autor).

Para Uricchio, certas formas de narrativa interativa apenas desagregam essas 'mini-narrativas' uma das outras dando ao espectador a possibilidade de agregá-las segundo seu interesse. "O DNA básico da narrativa - a sequência - permanece intacto, enquanto que o processo maior de junção é aberto à modificação promovida pelo usuário" (Uricchio, 2013).

A terceira estratégia deriva da narratologia cognitivista e define a narrativa como um processo cognitivo que é parte da estrutura psicológica humana. Seria assim um processo usual de ver e organizar a experiência vivida, mais do que uma característica do texto. Um processo defendido por outros autores que pensam na narrativa interativa (Murray, 2003; Landow, 2006). Sobre a narrativa como um processo cognitivo, Uricchio argumenta:

Criada e experienciada on the fly, é situacional e não tem a ver com ter que esperar um recontar post facto ou a agregação de mini-narrativas de forma a constituir uma experiência narrativa. Mas se manifesta na percepção da coerência e ligação entre eventos experienciados. (Uricchio, 2013, grifo meu).

O autor finaliza: 
Documentários interativos vêm de muitas formas diferentes, algumas das suas estruturas textuais aderindo bastante de perto a tradições narrativas estabelecidas; outras, explicitamente tomando a forma de mini-narrativas que o usuário pode mover entre e ligar; e outras ainda oferecendo ricas possibilidades desagregadoras ao participante motivado, que pode conectar os pontos numa experiência narrativa. (Uricchio, 2013).

Para Uricchio, os conceitos de play e de vaguear, andar ao acaso (wandering) servem portanto ao desenvolvimento de formas narrativas interativas. $\mathrm{O}$ autor aponta como razão para uma rápida incorporação dessas novas técnicas por documentaristas uma motivação para o play e o vaguear derivada de um contexto familiar, fruto da realidade histórica. Nas suas palavras, "a familiaridade preexistente do usuário com a realidade proporciona amplo contexto e motivação para que ele explore opções interativas e tendo-as coesas como uma experiência unificada e significativa" (Uricchio, 2013). A ficção exige a criação de um mundo diegético e a adaptação a este mundo antes que os usuários saiam navegando, vagueando de forma a vivenciar uma experiência significativa. Em ambos os casos, a estrutura textual do ambiente é apoiada na natureza da experiência a ser proporcionada ao usuário. Assim como a percepção da narrativa depende do afeto do usuário. Para o autor o play num mundo e o estar em um personagem podem beneficiar o contexto da não-ficção como opção criativa. Explorar olhando por outros olhos é uma estratégia que usa a imaginação como recurso e propicia um engajamento com uma dada agenda.

Uricchio portanto adota a experiência de se vaguear como bastante proveitosa no contexto da não-ficção já que o andar sem rumo a explorar dáse enquadrado pela realidade histórica, algo naturalmente contextualizado e motivante para o autor. 
Uma das grandes potencialidades do documentário interativo é a flexibilidade que ele propicia ao usuário de encontrar seu próprio caminho através de um ambiente construído. (...) no ato de playing (em vez de ouvir a história contada), nós temos a oportunidade de assumir um conjunto de instintos, de inventar uma posição de visionamento e de representá-la, de responder por meio dela, e no processo, aprender. $\mathrm{O}$ documentário interativo de hoje atende o andarilho sem rumo, e com um efeito maravilhoso. Mas tem uma capacidade ainda subutilizada de endereçar o player. (Uricchio, 2013).

\section{Conclusão}

O universo do documentário interativo, especificamente do webdocumentário, tem mostrado resultados no investimento da pesquisa acadêmica, pois requer que questões sejam pensadas unindo estudos de campos diferenciados. Como tentamos demonstrar aqui, é preciso buscar autores que trabalham com cultura digital e voltar os achados para o documentário, pois o documentário em si suscita questões próprias. Encontra-se reflexão importante sobre interatividade, autoria e participação em textos que lidam especificamente com o documentário interativo.

Interatividade é um conceito-chave, autoria, uma questão central e participação a grande potencialidade. Do lugar do autor, cabe a ele pensar na experiência que quer proporcionar, o quanto de controle quer ceder ao espectador-usuário, de que forma vai abrir o projeto para uma participação e até quando. E como a participação estará enquadrada em relação ao discurso do documentário. Do ponto de vista do espectador-usuário, espera-se engajamento físico para fazer acontecer o documentário e adesão às propostas de participação. É importante que o projeto contemple níveis de participação, pois nem todos querem participar da mesma maneira. A inversão de papéis entre autor e espectador é uma das grandes novidades trazidas pela interatividade, mas nem todos projetos vão investir nisso. Há 
que se perceber que no universo dos documentário interativos aquele chamado colaborativo é apenas um tipo.

Pensar a experiência proporcionada pelo documentário interativo a partir dos estudos de games, define um aspecto e abre outros sobre questões de narrativa. Podemos trabalhar com o pressuposto de que o play não exige a busca por um fim, o que conta é a experiência dentro do tempo em que se está jogando/brincando. Dito de outra forma, o play - entendido como brincar/jogar com o tempo - implica numa relação diferenciada de se entrar em contato com o conteúdo de um documentário interativo. Ainda assim, pensamos ser fundamental investigar outros pontos dentro desse espectro de estudo que é o viés narrativo da história. Pensamos ser proveitoso portanto pensar a análise do produto na sua arquitetura hipertextual tomando como norteadores a construção da história (início, meio e fim nas micro-narrativas e no todo e interface como conteúdo), a organização do tempo (da coisa narrada e da narração) e espaço (desenho da navegação, percepção dos mecanismos que orientam o espectador usuário na sua experiência).

Sabe-se desde já que alguns webdocumentários quando organizados como mosaicos podem não ter início, meio e fim, mas investir no enquadramento do assunto através de uma interface contextual e uma pequena introdução do assunto, tendo como grande qualidade a apresentação de múltiplas vozes, ou pontos de vista sociais. Outros irão investir apenas na partida, como diz Landow, sendo a chegada diferente a depender da navegação escolhida, do caminho traçado. Desenhar a história no espaço (interface e navegação) é fundamental para nortear o espectadorusuário que agora pode visualizar o percurso como um mapa a ser percorrido. Entender que o sentido de desorientação pode ser uma experiência estética planejada, justifica-se em algum sentido dentro da experiência do play. O tempo da coisa narrada pode ser uma brincadeira ou jogo no qual vale o tempo que o espectador-usuário quer destinar à experiência. 
Nem todos os webdocumentários vão adotar certas estratégias da mesma forma e embora alguns usem estratégias narrativas tradicionais buscando orientar o espectador-usuário, há ainda um investimento numa experiência personalizada que se dá na variação de tempo destinada ao vaguear pela história. A combinação tempo-espaço traz inevitavelmente a ideia de experiência on the fly, ou seja, do tempo gasto para se navegar pela história. Nesse sentido a noção de play introduzida por Uricchio como o engajar-se fluidamente, estar imerso na narrativa, achar sua própria forma dentro da narrativa, nos parece bastante proveitosa na definição da experiência múltipla que requer a apreciação de um documentário interativo.

\section{Referências bibliográficas}

BETWEEN THE LINES FESTIVAL (2013), Storytelling in the new landscape: the medium and the message. Disponível em: http://vimeo.com/70396815.

BOLTER, J. David; GRUSIN, Richard (2000), Remediation: understanding new media, Cambridge, Mass: MIT Press.

GAUDENZI, Sandra (2014), "Strategies of participation: the who, what and when of collaborative documentaries" in Kate NASH,; Craig HIGH,; Catherine SUMMERHAYES, (eds.), New documentary ecologies: emerging platforms, practices and discourses, UK: Palgrave Macmillan.

GIFREU, Arnau (2013-2014), MIT open documentary lab video profiles, Disponível em: http://opendoclab.mit.edu/category/video-profiles. (2013a), The distinction between linear and interactive documentaries (Partes 1 a 4). MIT open documentary lab research forum. Disponível em: http://opendoclab.mit.edu/category/ research-forum. 
(2013b), El documental interactivo como nuevo género audiovisual: estudio de la aparición del nuevo género, aproximación a su definición y propuesta de taxonomía y de un modelo de análisis a efectos de evaluación, diseño y producción, Barcelona: Tese de doutorado, Universidad Pompeu Fabra, capítulo 5, pp. 258-350.

LANDOW, George P. (2006), Hypertext 3.0: critical theory and new media in an era of globalization, Baltimore: Johns Hopkins, $3^{\text {a }}$ Ed.

MURRAY, Janet H. (2003), Hamlet no holodeck: o futuro da narrativa no ciberespaço, São Paulo: Itaú Cultural; UNESP.

__ Inventing the médium. Disponível em: http://inventingthemedium. com/glossary/.

NASH, Kate, (2014) "Clicking on the world: documentary representation and interactivity" in Kate NASH,; Craig HIGH,; Catherine SUMMERHAYES, (eds.), New documentary ecologies: emerging platforms, practices and discourses, UK: Palgrave Macmillan.

LEVIN, Tatiana (2013), “Do documentário ao webdoc: questões em jogo num cenário interativo" in Doc on-line: revista digital de cinema documentário, Covilhã, PT; Campinas, BR, n. 14, ago, 2013. Semestral. ISSN 1646-477X. Disponível em: http://www.doc.ubi.pt/index14.html.

(2010), “'Eu falo de nós para vocês': subjetividade e performance no documentário os catadores e eu" in Doc on-line: Revista Digital de Cinema Documentário, Covilhã, PT; Campinas, BR, n. 09, dez, 2010. Disponível em http://www.doc.ubi.pt/ index09.html. (2009), A "cinescrita" de Agnés Varda: a subjetividade incorporada ao campo do documentário, Salvador: Dissertação de Mestrado, Universidade Federal da Bahia.

S/ Autor, History of computers and computing, internet, dreamers, Vannevar Bush. Disponível em: http://historycomputer.com/Internet/Dreamers/ Bush. html. 
Tatiana Levin

Upian | IDFA DocLab. Disponível em: http://www.doclab.org/company/ upian/.

URICCHIO, Willian (2013), Playing with narrative in MIT Open Documentary Lab Research Forum. Disponível em: http://opendoclab.mit.edu/category/research-forum.

\section{Webdocumentários}

Gaza Sderot, life in spite of everything (2008). Disponível em: http://gazasderot.arte.tv/.

Highrise: out my window (2010). Disponível em: http://highrise.nfb.ca/. Prison Valley (2008). Disponível em: http://prisonvalley.arte.tv/?lang=en. 